\title{
АНАЛИЗ СОСТОЯНИЯ И ПРОБЛЕМЫ РАЗВИТИЯ РОССИЙСКОГО РЫНКА ЦЕННЫХ БУМАГ
}

\author{
(c) 2020 Михайлов Александр Михайлович \\ доктор экономических наук, профессор \\ Самарский государственный экономический университет, Россия, Самара \\ E-mail: 2427994@mail.ru \\ (C) 2020 Мишина Мария Сергеевна \\ Самарский государственный экономический университет, Россия, Самара \\ E-mail:ai496302@gmail.com
}

Ценные бумаги в настоящее время являются одним из более гибких финансовых инструментов. Также их можно считать одним из основных атрибутов относительно любого оборота. Будучи участником товарооборота, они могут являться одним из способов кредитования, а также средством платежа, заменяя при этом наличные деньги. В условиях рыночной экономики российский рынок ценных бумаг не справляется с многообразием задач и проблем, которые тормозят его дальнейшее развитие.

Ключевые слова: российский рынок ценных бумаг, рынок акций, ценные бумаги, динамика индексов, регулирование, конфликт интересов, капитализация, информационные технологии.

В плановой экономике существовали некоторые виды ценных бумаг, которые находили свое применение в имущественных отношениях. В момент перехода к рыночной экономике и в процессе формирования рынка ценных бумаг (РЦБ), возникла необходимость использования многообразия ценных бумаг. Таким образом, было положено начало в изучении спектра тех возможностей, которые предоставляются рынком, а также введение четкой юридической значимости ценных бумаг [2].

Российский рынок ценных бумаг начал свое существование более двадцати лет назад. Следует отметить, что не до конца сформированный рынок чаще всего вызывает определенные проблемы, которые связаны непосредственно с функцией регулирования, а также контроля данной экономической среды. Однако, несмотря на методы усовершенствования инструментов правовой основы российского рынка ценных бумаг, одновременное, ужесточение контроля за данной сферой экономики, а также регулирование отношений всех участников РЦБ возникают риски, которые так или иначе связаны с процессом создания финансового мегарегулятора Банка России. Ряд функций, которые ранее выполнялись Федеральной службой по финансовым рынкам в области контроля, регулирования и надзора в отношении некредитных финансовых организаций, были переданы его структурным подразделениям [1]. Итак, перечислим основные риски:

1. Использование Центробанком однотипных методов регулирования в отношении банковского рынка и рынка ценных бумаг. Банк России, осуществляя свою деятельность, может не выявить различия между банковскими и небанковскими сферами, что повлияет на развитие фондового сектора.

2. Возникновение конфликта интересов на фоне осуществления Банком России одновременно контролирующей и регулирующей функции и статуса участника рынка ценных бумаг.

3. Вследствие нехватки кадров, компетентных в решении вопросов, связанных с деятельностью на рынке ценных бумаг. У Центрального банка могут возникнуть трудности в решении тех или иных вопросов, так как данная отрасль финансового сектора имеет свою специфику.

4. Сокращение полномочий саморегулируемых организаций. Банк России не имеет полноценного опыта взаимодействия с Ассоциацией участников вексельного рынка или Национальной ассоциацией участников фондового рынка [3].

Таким образом, на современном этапе функционирования российского рынка ценных бумаг система его регулирования и контроля совершенна не в полном объеме из-за наличия вышеуказанных рисков, а также чрезмерной центра- 
лизации регулирующих полномочий.

Необходимость развития российского рынка ценных бумаг обуславливается его низким инвестиционным качеством. Данная характеристика присуща развивающимся рынкам. Российский рынок ценных бумаг отличается высокой волатильностью. Он нуждается в развитой инфраструктуре, новейших технологиях, финансовых продуктах, квалифицированных сотрудниках и т.д. На данный момент РЦБ находиться в зависимости от резких скачков мировых цен на нефть и от колебаний обменного курса национальной валюты [4].

Как показано на Рисунке 1 в 2018 году рынок акций Российской Федерации продемонстрировал разнонаправленную динамику: индекс МосБиржи вырос на 12,3\%, индекс РТС снизился на 7,42\%.

Еще совсем недавно, основным сегментом рынка ценных бумаг, являлся сектор государственных ценных бумаг. Он предоставлял краткосрочные ценные бумаги, которые в свою очередь являются объектом денежного, а не фондового рынка. Рынок корпоративных ценных бумаг начинает стагнацию или занимается обслуживанием инвесторов, зачастую иностранных. Следует отметить, что население России играет немаловажную роль в развитии отечественного рынка ценных бумаг.
Российский рынок ценных бумаг в настоящее время нуждается в переориентации своих ресурсов. Обеспечение быстрорастущих потребностей государства, перераспределение крупных портфелей акций и развитие спекулятивного ажиотажа вокруг новых финансовых организаций - все это должно перейти на второй план. Вначале необходимо выполнить свою первоочередную функцию - увеличить количество денежных ресурсов, направить их на восстановление и развитие производства в России, тем самым преодолеть инвестиционный застой. Чем крупнее рынок, тем в более профессиональном регулировании он нуждается. Это необходимо для предотвращения обвала на РЦБ. Уже сейчас на разных уровнях экономики в структуру рынка ценных бумаг необходимо внедрение элементов долгосрочного стратегического управления [7].

Одним из наиболее известных индикаторов рынка ценных бумаг является капитализация. Капитализация в данном контексте понимается как суммарная рыночная стоимость обращающихся на этом рынке ценных бумаг. Показатели для России и США представлены в Таблице 1 следующим образом:

2016 год знаменуется падением показателей капитализации по всем мировым фондовым площадкам. Можно увидеть, что в 2016 году капитализация рынка значительно замедлилась. В

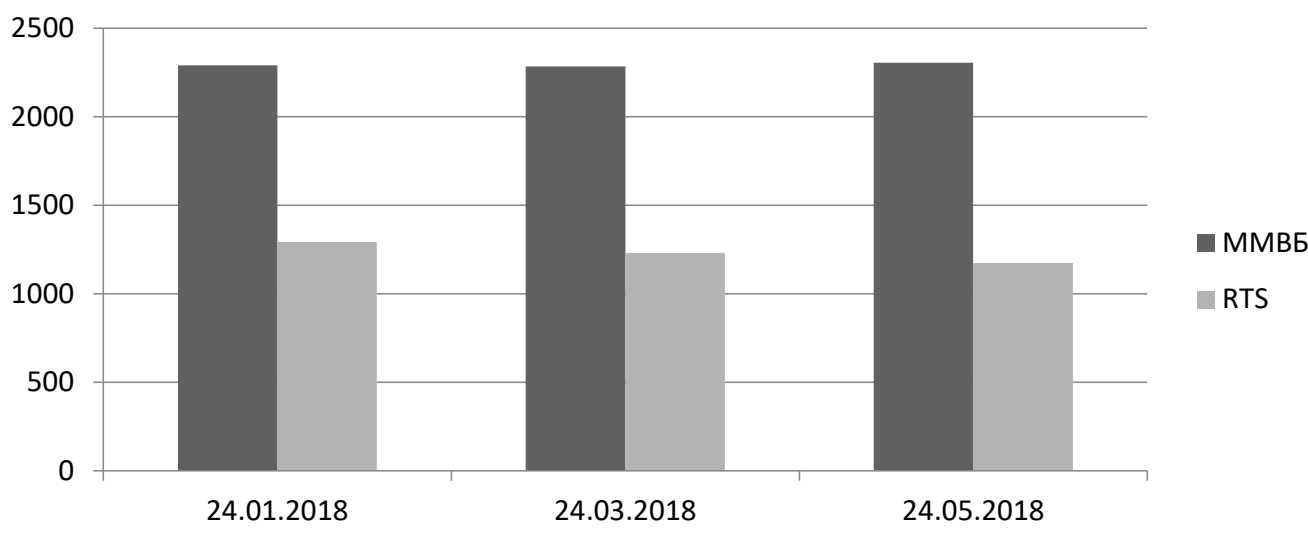

Puc. 1. Динамика индекса ММВБ и РТS Источник: URL: http://www.finam.ru/

Таблица 1. Капитализация рынка ценных бумаг России и США в 2015-2018 г.г. млн. долл.

\begin{tabular}{|c|c|c|}
\hline Год & Россия & США \\
\hline 2015 & 711775 & 11737645 \\
\hline 2016 & 751770 & 12122581 \\
\hline 2017 & 942320 & 14678487 \\
\hline 2018 & 833936 & 15155378 \\
\hline
\end{tabular}


следующем году российские компании смогли частично восстановить потери, в результате чего динамика капитализации не отличалась от динамики США.

Несмотря большой разрыв между показателями Америки и России стоит отметить, что колебания на российском уровне не имеют особых отличий от других развивающихся стран. По сравнению с 2016 г. рыночная капитализация на российском рынке ценных бумаг в 2018 г. увеличилась на 82,2 млн. долл., а на рынке США в 2018 г. показатели поднялись в 1,3 раза [9]. Исходя из проведенного анализа, можно сделать вывод, что перспективы для дальнейшего роста в посткризисном периоде являются положительными.

Процесс становления российского рынка ценных бумаг привел к образованию большого количества проблем, которые непосредственно связаны с этим процессом. Их решение, в первую очередь, необходимо для успешного функционирования и развития рынка в будущем.

Для дальнейшего эффективного развития РЦБ необходимо рассмотреть и решить ряд задач [8]:

1. Минимизировать отрицательное влияние внешних факторов на РЦБ. К ним относятся экономический кризис, политическая нестабильность, социальные конфликты.

2. Переориентировать РЦБ с первоочередного обслуживания финансовых запасов государства на увеличение тенденции роста независимых экономических ресурсов в возобновление и формирование производства в Российской Федерации.

3. Модернизировать действующее законодательство и усилить контроль за его соблюдением всеми участниками РЦБ.

4. Увеличить роль страны на рынке ценных бумаг, для этого необходимо сформировать:

- общегосударственную долговременную политику, направленную на увеличение эффективности действия РЦБ с ее последующей регулировкой (составление идеальной модели рынка ценных бумаг);

- компетентную комиссию по выпуску ценных бумаг и регулированию фондового рынка, основной задачей которой, будет являться объединение ресурсов государства и предпринимательского сектора для создания идеального рынка ценных бумаг.

5. Создать депозитарную клиринговую сеть, агентскую компанию для осуществления контроля движения и выпуска ценных бумаг в интересах эмитентов.

6. Обеспечить защиту инвесторов от потерь, связанных с ценными бумагами. Для этого создать компетентный орган, действующий на государственном уровне и обеспечивающий безопасные условия на РЦБ.

7. Осуществить принцип открытости сведений методом расширения публикаций о деятельности эмитентов ценных бумаг, находящихся в свободном доступе, адаптировать общепринятый рейтинг фирм, осуществляющих выпуск ценных бумаг, обобщить сети специальных изданий, которые определяют отдельные сферы в качестве объектов вложений, заключение общенародного плана характеристик для оценки торга ценных бумаг и т.д.

На данном этапе рассмотрим основные направления совершенствования российского рынка ценных бумаг:

- Концентрация и локализация денежных потоков;

- Глобализация и интернационализация рыночной сферы [5];

- Улучшение показателей компаний и ужесточение государственного контролирования;

- Внедрение новейших информационных технологий в сфере развития рынка ценных бумаг;

- Увеличение инноваций на РЦБ;

- Стремительная трансформация;

- Взаимодействие рынка ценных бумаг с другими рынками денежных средств.

Направленность рынка ценных бумаг к сосредоточению и централизации денежных потоков обусловливается несколькими признаками. Во-первых, главной целью данного аспекта является привлечение большего количества участников рынка, для которых данная работа считается основной. Во-вторых, происходит процесс выделения ведущих экспертов рынка на основе увеличения их личных денежных средств (сосредоточение денежных потоков), а также путем слияния этого капитала в более крупные рыночные структуры (концентрация денежных потоков). Вследствие чего, на РЦБ образовываются трейдерские организации, которые контролируют большую часть всех транзакционных операций на рынке. Таким образом, РЦБ получает больший приток денежных средств населения.

Интернационализация РЦБ означает, что ос- 
новные денежные средства государства пересекают его границы и образуется мировой рынок ценных бумаг. Он в свою очередь, отодвигает государственные рынки на второй план. Биржа ценных бумаг также начинает носить мировой характер. Всемирная торговая деятельность создает непрекращающийся процесс, который лежит в основе ценных бумаг международных компаний.

Повышение надежности и уровня доверия к российскому рынку ценных бумаг со стороны инвесторов тесно связаны с улучшением уровня организации рынка и ужесточением мер контроля за его деятельностью. Размер и роль рынка ценных бумаг настолько велики, что его постепенное разрушение приведет к снижению финансового прогресса. Государство должно обеспечить такое доверие к РЦБ, при котором потенциальные инвесторы будут уверены, что они не потеряют свои денежные средства в случае той или иной деятельности государства или при актах мошенничества. Все участники рынка ценных бумаг напрямую заинтересованы в его дальнейшей централизации и особом контроле со стороны государства [6].

Создание новых информационных технологий в деятельности РЦБ - это внедрение современных приложений и программ, базовая платформа которых полностью автоматизирована и дает возможность производить разнообразные операции с ценными бумагами без помощи посредников, исключающая прямые договора между продавцами и покупателями. Новые информационные технологии дают также возможность получения доступа на международные площадки фондовых рынков.

Секьюритизация направлена на привлечение большего количества активов для дальнейшего их перевода в ценные бумаги. Для обеспечения эффективной и бесперебойной работы рынка ценных бумаг, секьюритизация должна включать в себя грамотный мониторинг контролирующих органов власти, реальный подсчет величины имеющихся ресурсов и усиление мер по более грамотному отбору потенциальных заемщиков.

Развитие российского рынка ценных бумаг никак не может привести к исчезновению иных рынков денежных средств, наоборот, совершается процедура их взаимопроникновения. С одной стороны, деньги и капитал могут быть выражены в виде ценных бумаг, а с другой стороны, ценные бумаги могут быть средством платежей, накоплений и инвестирования.

В заключении, следует отметить, что на успешное развитие и дальнейшую эффективную деятельность российского рынка ценных бумаг влияют доверительные отношения между всеми участниками данного рынка, совершенствование законодательной и правой основы, стратегическое планирование, которое позволило бы закончить процедуру приватизации. Рынок ценных бумаг играет большую роль в развитии экономики страны. Опыт цивилизованных государств показывает, что ценные бумаги акционерных сообществ составляют большую часть на РЦБ. В Российской Федерации ведущая роль принадлежит государственным ценным бумагам.

\section{Библиографический список}

1. Значкова Н. В. Анализ состояния рынка ценных бумаг России на современном этапе // Научное сообщество студентов: Междисциплинарные исследования. 2017 № 1(12). С. 32-33.

2. Коновалова М.Е., Кузьмина О. Ю., Левченко Л. В. Мировой рынок ценных бумаги тенденции его развития. Вопросы экономики и права. 2018. № 121. С. 58-61.

3. Лансков П. М.Артюшенко В.А. Управление рисками и возможности оценки достаточности средств в учетных институтах рынка ценных бумаг // РЦБ. 2016. С. 54-56.

4. Михайлов А.М., Искандаров Т. С., Городнов В. А. Роль фондового рынка в финансировании экономики. //Экономические науки. 2019. № 173. С. 22-26.

5. Михайлов А.М., Пономарева М. В. Развитие фондовых рынков под воздействием процесса глобализации // Проблемы развития предприятий: теория и практика. 2018. № 1 С. 27-29.

6. Мишина М.С., Михайлов А. М. Развитие рынка государственных ценных бумаг в России//Актуальные аспекты развития современной науки. 2019. № 1. С. 87-89.

7. Покровская Н.Н., Куриленко М. В. Рынок государственных ценных бумаг в России: проблемы и перспективы развития // Интернет-журнал «Науковедение». 2016. Том 8, № 4.

8. Тимерьянова Ф. Р. Ключевые проблемы развития рынка ценных бумаг в РФ // NovaInfo.Ru. 2016. № 44. С. 5-9.

9. Федеральная служба государственной статистики [Электронный ресурc]. URL: http://www.gks.ru/. 